\author{
Krystian SICZEK, Krzysztof SICZEK
}

\title{
MODERN VEHICLES FOR REFRIGERATION
}

The article contains an overview of modern solutions for refrigerated vehicles. The most important manufacturers of refrigerated trailers were described. Then, solutions based on adaptation of a refrigeration vehicle were discussed. The characteristics of popular trailers, trailers and bodies used as refrigerators were presented. The telematics systems and aggregates used in refrigerated vehicles were also discussed in the article.

\section{INTRODUCTION}

The group of a dozen percentage of the total number of semitrailers manufactured in $\mathbf{2 0 1 6}$ for customers in Poland constituted 2,647 refrigerated trucks and 57 isotherms [1].

This represents an increase of almost 30\% compared to 2015 [1]. In addition to semi-trailers, refrigerated trucks also use trailers and vehicles with special bodies. The offer of manufacturers of such vehicles is constantly growing.

Vehicles for transporting goods under controlled temperature conditions are used to transport perishable goods, especially food and pharmaceuticals. The transport of such goods must meet strict sanitary standards resulting, inter alia, from the requirements of the HACCP system. In terms of design, individual solutions are like each other. The construction of isotherms and cold stores is based on aluminium panels, a polyester-glass film, often called a laminate, and the insulator is a rigid polyurethane foam or polystyrene [1].

\section{THE MOST IMPORTANT MANUFACTURERS OF REFRIGERATED TRAILERS}

Schmitz Cargobull [2] and Krone have been leading the market for years, producing $90 \%$ of all refrigerator trucks and isotherms. The construction of the Krone body on an independent frame ensures very high durability. In the case of traffic accident, it is possible to replace the body or chassis without the need to completely remove the vehicle. The Krone company offers a series of Cool Liner refrigeration trailers. It is possible to transport almost all products requiring controlled temperature, there are also semi-trailers with crane handles and appropriate equipment for combined transport (adapted to the Huckepack system). The series of Cool Liner semitrailers includes Pharma version (especially for drug transport) and City model, equipped with in elements protecting the trailer against the effects of frequent docking [1].

Another big representative on the trailer market is EWT Truck \& Trailer Poland (representative of Schmitz Cargobull). The main element of the S.KO COOL Executive set supplied by the company, used for transporting cargo in temperature-controlled conditions, is the SCB transport refrigeration unit, in combination with the S.KO COOL semi-trailer. The set is supported by a special package including stepless regulation of cooling power, innovative design of the evaporator, independent air circulation. It is possible to control using telematics (it secures transport and business operations because valuable goods are better supervised) [1].

The Kögel semi-trailers are well-recognized on the Polish market, including the Cool van PurFerro quality semi-trailer [3] with so- called. quiet aluminium floor construction, reducing the noise generated during loading and unloading. This vehicle has a series of load securing certificates as per DIN EN 12642 Code XL. It is predestined for transporting general cargo and goods transported on pallets [1].

The Wielton company is among the leading domestic producers of refrigerator trucks stores and isotherms. Its NS3CM2 semitrailer together with the aggregate and the pallet box weighs just over $8 \mathrm{t}$. Adhesive construction made of "sandwich" type plates, insulated with polyurethane-free polyurethane foam. The refrigerator truck floor was adapted for driving a fork carriage with $5.4 \mathrm{t}$ of pressure on the bogie axle. Optionally, the floor is fully lined with aluminium sheet [1].

The Schwarzmueller company present on the Polish market builds refrigerator trucks based on a steel, welded light frame construction (frame cold store). The free space of such a cold store allows you to load 36 euro-pallets. Doppelstock solutions (dual loading systems) are also available [1].

The market is also operated by VéDéCar, a Benelux manufacturer. All VéDéCar semi-trailers can be equipped with longitudinal or transverse barriers (fixed and movable). Optionally, side (one or two-wing) side doors are offered. It is possible to use two aggregates, which allows the interior to be divided (up to six temperature compartments) [1].

\section{SOLUTIONS BASED ON THE ADAPTATION OF VEHICLES FOR REFRIGERATION}

Specialized building projects are growing in popularity and constitute an interesting offer of companies such as Lamar. For transporting goods at low temperatures, the company adapts vans and chassis of leading manufacturers such as: Fiat, Peugeot, Citroen, Mercedes-Benz, Iveco, Opel, Volkswagen or Renault Trucks. The large offer has, among other isotherms and refrigerator units [1].

Isotherms is a proposal for carriers requiring a relatively stable temperature in the range of $273-293 \mathrm{~K}$. After installing an additional heating device in the cargo space, we can get up to $303 \mathrm{~K}$. The emphasis is on the low coefficient of thermal permeability, and the structure is made of sandwich panels. The whole is covered with a polyester-glass laminate, easy to keep clean [1].

The range of company solutions is supported by refrigerator units, which are armed with thicker walls than isotherms. The temperature in the hold is in the range of $253-273 \mathrm{~K}$. The structure of the entire structure is created by high quality laminate. The roofing reduces the risk of mechanical damage during intensive use. In both solutions (isotherms and refrigerator units), their functional ad- 
vantages are significantly raised by additional equipment (e.g. movable or fixed bulkhead divides the loading bay into two independent chambers, mid-air aerodynamics or cargo fastening strips). The cooling chillers used come from such producers as Zanotti [4], Thermo King [5] or Carrier [6].

In addition to the isotherms and refrigerator units, obtaining the desired temperature is possible by using Lamar Cool isothermal cartridges. The skeleton of this patented and certified construction, adopted in popular vans, is isothermal panels. They are made of polyester-glass laminate. The advantage of this modern, environmentally friendly technology are high adaptive properties. The panels fit into the inner outline of the van, which on the one hand minimizes the phenomenon of the so-called thermal bridges, and on the other, allows you to maximize the interior of the hold. This solution ensures maximum tightness and reduces the risk of cooling down, heat loss or excessive heating of the inside of the van. An interesting fact is that in the event of damage it is possible to replace only a part of the plating, not the entire wall, as in the case of a container. In addition, this is done without loss of quality and insulating properties. The usefulness of the product is increased by additional equipment, such as movable shelves with load securing slats, and everyday comfort and ergonomics, belt curtains or additional cargo securing points [1].

Recently, the company D.A.C. has launched an interesting solution in the form of a van converted into a refrigerator track. The cooling part uses space, wall, ceiling and floor insulation, an additional anti-slip floor made of corrugated aluminium sheet and wheel arch protection secured against damage in the lower part of the inner walls. The van - refrigerator truck received also cargo space lighting system (LED), two rows of transport slats and strut bars. A servomotor was mounted to the side door of the loading part, preventing possible damages, which may be caused by wind gusts [1].

\section{TELEMATICS SYSTEMS' DEVELOPERS}

More and more often, telematics systems, called telematics, are coming in shorter with the help of carriers. Modern systems protect against interference of unauthorized persons, there are also common procedures for solutions in the event of failures and fortuitous events (emergency procedures).

Schmitz Cargobull offers factory telematics under the name TrailerConnect. This system, in addition to the basic vehicle positioning function, provides various telematic data, such as: mileage, door opening / closing status, cargo space temperature, number of operating hours and alarm states of the refrigeration unit, also the battery charge status of the aggregate in the case of a trailer equipped with a refrigeration unit. You can also check the loading status of the vehicle and all data from EBS [1].

Blulog [8] offers temperature and humidity recorders, intended for cold storage cars. The basic recorder measures temperature and records measurements in each place every 10 minutes. The measurement precision is $0.2 \mathrm{~K}$ for the temperature range of $273-303 \mathrm{~K}$ and $0.5 \mathrm{~K}$ for the remaining parts of the temperature range 233 $343 \mathrm{~K}$. The system can generate alerts in real time (SMS notifications or emails, if the temperature limit is exceeded). Blulog recorders were used, among others in Coolbox 4.0 (a Georg Utz product). It is the first transport container on the market, equipped with an electronic system that allows obtaining information on the temperature and geolocation of the load, without the need to provide an external power source. The LED immediately indicates whether the cooling chain has been damaged during transport. Access to geolocation data takes place via the mobile phone network, without the need to recharge the battery. This solution is practically mainte- nance-free. Verification of parameters takes place at a set time, even every 10 seconds (registration of the ambient temperature in the temperature range $233-333 \mathrm{~K}$ ). It is possible to program an alert if the limit temperature limits for the set cold chain are exceeded [1].

Loggicar's measurement logging systems [9] have been on the market for a long time. Recently, their range has been extended with the Loggicar $\mathrm{R}$ device - a radio recorder designed to monitor temperatures and humidity in car refrigerators (the offer includes cable recorders: Loggicar $\mathrm{C}$ and Standard). Communication between the recorder and sensors is carried out via radio waves. It can be connected wirelessly with four temperature-humidity sensors (e.g. cold store, evaporator air inlet and outlet, product temperature) and four bistable signals (opening of side and rear doors, defrosting, operation of aggregate aggregate) [1].

There is also TX1 device on the market, which is a separate temperature recorder that is part of the Krone Telematics system. It is based on a set of certified temperature sensors evenly distributed in the cargo space of the semi-trailer. They send information about the temperature in the chamber or in the trailer chambers directly to the Krone Telematics system. This information in aggregate form reaches the server, at precisely defined time intervals, user-defined trailers. The data can be displayed and analysed, and the temperature course can be saved in a * .pdf file, creating a document confirming the transport of the goods at the optimal temperature for the end user [1].

Carrier Transicold also announced a customized telematics solution delivering advanced capabilities for its transport refrigeration units (TRUs). The new telematics solution can help fleets manage their refrigerated assets by enabling remote refrigeration unit monitoring, control and diagnostics, data management and other valueadded capabilities. It can provide an advanced two-way wireless communications system, uniquely qualified for truck and trailer units and backed by CT comprehensive dealer support network [7].

\section{CHARACTERISTICS OF POPULAR SEMI-TRAILERS, TRAILERS AND BODIES}

D.A.C. specializes in constructing various versions of thermally insulated bodies. The company can adapt the van to the cold store. Depending on the constant desired temperature inside the building, the thickness of the walls, floor, roof and door are selected. The floor made of corrugated aluminium sheet or spout, depending on the conditions imposed by the customer, is insulated on both sides with foil-coated plywood. The individual elements are part of the ultra-light self-supporting sandwich construction. Thermal insulation is provided by hardened polyurethane foam without thermal bridges, with sheathing. The equipment is made of stainless, acid-proof steel. Carrier [6], Thermo King [5] and Zanotti [4] aggregates are used.

The improved premium refrigerated semi-trailer: Kögel Cool PurFerro [3] quality can have new options and special sets of equipment tailored to the client's requirements. Among them there are, for example, a device for lifting the first and third axles, an articulated torsion axle or a fifth wheel coupling with a load capacity of up to $15 \mathrm{t}$. Silent, aluminium floor construction reduces the noise generated during loading and unloading. The welded aluminium bath ensures better hygiene and easier cleaning of the floor. The van's semi-trailer body consists of a freon-free foam with improved insulating properties. 45 or $60 \mathrm{~mm}$ thick walls, $85 \mathrm{~mm}$ thick roof and $125 \mathrm{~mm}$ thick floor (own production) ensure high values of heat transfer coefficient. 
Krone Cool Liner is available in the following versions: standard, multi-temperature, two-story and so-called hook-like (in the last of these solutions, the roof panel is $50 \mathrm{~mm}$ thicker). The frame of the semi-trailer has a reinforcement running upwards in front. It stabilizes the front wall and protects against damage when connecting the semi-trailer to the tractor's saddle. The roof was equipped with an air apron, so-called flexible air duct for even distribution of cold air throughout the trailer. This solution is also suitable for stack loading. Multi-chamber versions are optionally available. Inside the vehicle, light metal profiles with an increased cross-section on the front wall are used. A watertight, continuous floor bathtub is welded directly to the fender bars. In the rear part, it is additionally reinforced, due to the need to take heavy loads from the forklift. Combined transport in different temperature zones is possible thanks to Isowall MultiTemp thermal partition wall [1].

Lamar also provides comprehensive solutions for the construction of commercial vehicles and vans. The most popular solution is the LAMBox body. It has a cubic capacity of up to $22.5 \mathrm{~m}^{3}$. The Lamar company also offers isotherms and cold stores. In addition to the basic insulated containers, cold stores and isotherms, the offer also includes system thermal inserts Lamar Cool, i.e. isotherms and cold stores for vans. Lamar Cool is an isothermal panel designed individually for a given vehicle model, reflecting the inner paneling of the van. Thanks to this, they minimize the formation of thermal bridges. One of the two types of Lamar Cool buildings are isotherms ( $\geq 0$ deg. C) for transporting or distributing goods requiring a stable positive temperature. The other is refrigerated construction $\left(\leq-20^{\circ}\right.$ C) for vans up to $3.5 \mathrm{t}$ (including for the transport of frozen foods, ice cream or cold cuts) [1].

Lecitrailer manufactures refrigeration vans with a solid and innovative structure. Carrier's Vector 1550 and ThermoKing refrigeration systems regulate the temperature and cooling parameters of the trailer depending on the type of product being transported. Refrigerators are characterized by a thin-walled structure reducing the mass of the vehicle, an external execution using polyester and an internal coating with varnish adapted to the requirements of food processing. A new variant of the Lecitrailer cold store is a vehicle with a swan neck type chassis, available as a premium version with a standard $35 \mathrm{~mm}$ thickness [1].

The Schmitz Cargobull [2] uses a gluing technique in its solutions without the use of rivets and screws. The glued bodies are resistant to torsion and bending. Ferroplast boards, consisting of a double layer of metal filled with multilayer insulating foam, are used for construction. Ferroplast is more resistant to water vapor diffusion and mechanical damage than other walls. The combination with a fully welded aluminium insert securing the bottom facilitates hygiene and cleaning. Schmitz Cargobull supplies MROKO refrigeration and isothermal building with two wall thicknesses (45 or $65 \mathrm{~mm}$ ). The S.KO series is also produced, including the two-level version. The double deck allows loading 66 euro-pallets, in the configuration: 33 Euro-pallets on the floor, and another 33 on special transverse beams fixed in the side walls. An insulated partition wall is an option [1].

The company Schwarzmuller manufactures refrigerated buildings on trucks, trailers and refrigerated semitrailers. The constructions are based on plastic. The GFK glass composite is used inside. In turn, the outer part of the building is insulated with a special polyurethane foam. This type of construction is characterized by the lack of thermal bridges, is resistant to condensation processes, and the penetration coefficient is $0.3 \mathrm{~W}$. Cooling units of Carrier or Thermo King brands are used. The Schwarzmuller company also manufactures the Doppelstock refrigeration (dual loading system), hook refrigerated trucks and bodies adapted for transporting flow- ers. Frame constructions are galvanized and varnished. The weight of the semi-trailer is of $7,700 \mathrm{~kg}$, with the aggregate and the pallet basket [1].

TMT has developed an innovative solution in the form of a movable floor with a cold store, considering the individual requirements of producers and distributors of food or fresh products. It is intended for the transport of loose food and / or products that require a controlled temperature. A typical TMT semi-trailer with movable floor has dimensions (length $\mathrm{x}$ width $\mathrm{x}$ height): $13.600 \mathrm{x} 2.470 \mathrm{x}$ $4000 \mathrm{~mm}$. The internal height is $2.67 \mathrm{~m}$, the cubature reaches $92 \mathrm{~m}$ 3 , and the cargo holds 33 euros. The welded structure is based on aluminium. The moving floor drive mechanism is the proven Cargo Floor system. The floor (21 plain slats) can be 6,8 or $10 \mathrm{~mm}$ thick. Cooling units are used for cooling: SLXe 300; Carrier Vector 1550 or Thermo King [1].

Van Dijck Merksplas, the owner of the VéDéCar brand, produces high-quality refrigerated trailers, as evidenced by the very low thermal permeability coefficient, $k=0.29$. The high rigidity of the monolithic building is achieved thanks to the use of composite, which is the plating of the building. The panels are made of polyester reinforced with fiberglass. The individual walls consist of one part. To produce floors and roofs, very light, durable and waterabsorbent wood from the Finnish birch is used. The standard VéDéCar trailer is $13.6 \mathrm{~m}$ long, the thickness of the front and roof is $100 \mathrm{~mm}$, and the floor is $120 \mathrm{~mm}$. Semi-trailers can be used in a double-deck version, allowing for the transport of 66 euro-pallets. Vehicle frames are made of high strength steel [1].

\section{AGGREGATES}

Drabpol, representing the Konvekta [10] brand in Poland, offers, among others, cooling $12 \mathrm{~V}$ electric aggregates for vans. For this vehicle category and for a specific application area (urban traffic), the FK 1120-E is dedicated. The refrigeration device is powered from the vehicle battery, and there is no need to install the compressor in the engine compartment. Aggregate FK 1120-E provides steady performance at outdoor temperatures up to $43^{\circ} \mathrm{C}$. The latest novelty is a two-chamber aggregate, intended for transporting fresh or frozen products. The advantage of this device is a narrow evaporator (width $480 \mathrm{~mm}$ ), which is very beneficial for multichamber buildings on smaller delivery vehicles and a flat condenser with a height of only $175 \mathrm{~mm}$. The parking cooling option has been integrated in the outdoor unit [1].

A novelty in the offer of the Thermo King company is the platform of SLXi semi-trailer units [5]. These single- or multitemperature devices have been developed with emphasis on intelligent solutions, communication options, fuel consumption, temperature control and environmental protection. The SLXi series is the result of long-term research, consultations with transport companies and analysis of data from aggregates tested under various conditions. All these activities allow you to adjust the operation of the device to the individual specifics of the transported cargo and full system optimization. The main features of the SLXi series are: telematic equipment as standard, the option of remote management of the unit and full access to operational data, improved temperature control, increased fuel economy, reduced environmental impact [1].

According to [6] Carrier Transicold released the smallest chiller on the market Basic 700. It is economical in operation and service, easy to assemble and reliable. The Basic 700 unit is very quiet thanks to the power supply from the car's electrical system. It is a refrigeration device recommended for night distribution in urban agglomerations. Basic 700 works with the use of ecological refrigerant R134a and is standard equipped with hot gas defrosting. De- 
pending on the configuration of the flat or head evaporator, the unit has a ventilation capacity of 460 or $560 \mathrm{~m} 3 / \mathrm{h}$, weight 68 or $63 \mathrm{~kg}$. With an outdoor temperature of $303 \mathrm{~K}$, the cooling capacity of the unit is 735 or $695 \mathrm{~W}$ for an internal temperature of $273 \mathrm{~K}$ and 290 or $230 \mathrm{~W}$ for 253 . The next popular refrigeration unit from Carrier is the Zephyr 540, driven from the vehicle's engine. It is characterized by low purchase, operation, high reliability and ease of use. Zephyr 540 works with the use of ecological refrigerant R134a. It has a ventilation capacity of $920 \mathrm{~m} 3 / \mathrm{h}$, a weight of $37 \mathrm{~kg}$. With an outdoor temperature of $303 \mathrm{~K}$, the cooling capacity of the unit is 1945 $\mathrm{W}$ for an internal temperature of $273 \mathrm{~K}$ and $780 \mathrm{~W}$ for $253 \mathrm{KFirma}$. Carrier Transicold has also produced a modern Xarios series of refrigeration units powered by the vehicle engine, including Xarios 150/200, Xarios 300 and 350, Xarios 400 and 500. The capacities of these aggregates are respectively $650,830,830,1540,1540$ and $2280 \mathrm{m3} / \mathrm{h}$, and their masses 42, 47, 57, 69, 120 and $129 \mathrm{~kg}$. With an outdoor temperature of $303 \mathrm{~K}$, the cooling capacity of the aggregates amounts to $1800,2300,2860,3360,4360$ and $4760 \mathrm{~W}$ respectively for an internal temperature of $273 \mathrm{~K}$ and $950,1300,1700$, 1900, 2442 and $2660 \mathrm{~W}$ for $253 \mathrm{~K}$. In turn, at an external temperature of $255 \mathrm{~K}$, heating capacities of the aggregates are respectively $1800,2200,2800,3100,3400$ and $3600 \mathrm{~W}$ for an internal temperature of $291 \mathrm{~K}$. These automotive chillers are characterized by high reliability and efficiency. They are equipped with the latest generation of mi-cochlear control and super flat evaporators. The most important features of refrigeration equipment belonging to the Xarios series: brushless with long-life turbine evaporator fans excluding maintenance service and ensure constant strong airflow, condensers of large aggregates, which allows the use of devices in climatic zones, new microprocessor control with a multi-functional fourposition control panel equipped with three time counters of the unit, a number of electrical protections and electronic components of the device, display of alarm states, low noise level, reduced operating costs. The aggregates use ecological refrigerant R404a. The aggregate option includes: hot gas heating (Xarios 500 standard), power supply from the mains, installation on the roof of the vehicle (except for Xarios 400/500), cooling installation opening sensor. Carrier Transicold also produced the Supra series of self-propelled chillers, including Supra 450/550, Supra 750, Supra 850/950. The capacity of these aggregates is $1611,2250,2200,2500$ and 2770 $\mathrm{m} 3 / \mathrm{h}$, and their masses 335, 386, 423, 455 and $590 \mathrm{~kg}$. With an outdoor temperature of $303 \mathrm{~K}$, the cooling capacity of the aggregates is $4470,5425,6765,7810$ and $10770 \mathrm{~W}$ for the internal temperature of $273 \mathrm{~K}$ and $2580,3080,3825,4910$ and $6450 \mathrm{~W}$ for 253 K. The ZS engine speed ranges successively to $1800 / 2320$, $1800 / 2320,1800 / 2200,1800 / 2320$ and 1800/2250 rpm. Fuel consumption at high speed is $1.1,1.3,1.8,1.8$ and $2.7 \mathrm{lph}$. The aggregates use ecological refrigerant R404a. These are new chillers with drive from the ZS engine designed for delivery vans. The new series of chillers used the latest technological achievements, allowing to achieve the minimum noise level, high reliability and easy operation thanks to EasyCOLD microprocessor control. The SUPRA series chillers used materials with increased resistance to external conditions. Direct access is provided through opening located in the top panel, to the oil level meter, refrigerant fluid and to refrigerant sight glasses. The use of EasyCOLD control reduces fuel consumption thanks to the automatic start / stop system and the reduction of inspection costs thanks to the self-diagnosis function. The large number of alarm states stored in the memory of the microprocessor controller greatly shortens the diagnostic time and minimizes driver mistakes. The unit options include: Nornic versions with increased heating capacity, fuel heater, fuel filter with water separator, additional control panel, temperature recorder, automatic phase correc- tion, noise reduction system, SAS. The company CARRIER Transicold has also released the Maxima series of trailer units, including Maxima 1000 and Maxima 1200 models.

The capacity of these aggregates is respectively 4600 and $5100 \mathrm{~m} 3 / \mathrm{h}$, and their weight is 765 and $795 \mathrm{~kg}$. With an outdoor temperature of $303 \mathrm{~K}$, the cooling capacity of the aggregates amounts to 10,200 and $12,000 \mathrm{~W}$ respectively for the internal temperature of $273 \mathrm{~K}$ and 10,2200 and $11,200 \mathrm{~W}$ for $253 \mathrm{~K}$. The Sa is a modern refrigeration unit intended for transporting goods in refrigerated trailers with a capacity of 33 euro-pallets and a length of 13.60 $\mathrm{m}$. The device was based on the previous version of the Maxima2 chiller. The Maxima 1200 device offers a new design, noise reduction achieved thanks to new housing elements and a new air filter, increased cooling ventilation, four times greater corrosion resistance, a new control panel, microprocessor control, start / stop system as standard equipment. Device named MAXIMA 1000 is designed for mounting on trailers. The lower housing belt is missing, which reduces the size of the unit, facilitates installation on towed vehicles. The control panel is mounted on the wall of the cooling installation. The unit's ZS engine works only at low revs, eliminating part of its components and increasing the service life of the drive unit. It also had an impact on reducing the volume of the aggregate, which is very important for urban distribution.

According to [4] Zanotti offers a series $Z$ of aggregates refrigeration equipment for vans including models Z20, Z25, Z35, Z38 with direct drive from the vehicle's engine. The offered capacities of the devices in this series allow their use in volumes of 6 to $33 \mathrm{~m}^{3}$, allowing a temperature of $0^{\circ} \mathrm{C}$ at an outdoor temperature of $+30^{\circ} \mathrm{C}$. These devices are available in options with 230 or $400 \mathrm{~V}$ power supply and can be retrofitted with the hot gas option. It is also possible to supply devices in a multi temperature version. Thanks to the high cooling and ventilation capacity, all $Z$ series devices can be used where a transport temperature of $-20^{\circ} \mathrm{C}$ is required. When the construction of the car does not allow the compressor to be mounted in the engine compartment, Zanotti offers Z10 or Z12 aggregates called alternator. These compressors drive the compressor using an electric motor powered by $12 \mathrm{~V}$ from the car's electrical system (an alternator with a minimum power of $90 \mathrm{~A}$ is required for efficient operation). The above models can be equipped with $230 \mathrm{~V}$ power supply and heating with hot gas. Another interesting solution offered by Zanotti are aggregates with a distinctive design of condenser that allows installation in the engine compartment or under the floor of the vehicle. Direct drive, no condenser on the roof, no interference with the roof structure, high cooling and ventilation capacity and the option of heating with hot gas are the characteristics of the aggregates FZ007, FZ008, FZ009. The FZ series devices are used in cars of panel van types, allowing effective work also in deep freezing temperatures for bodies with cubatures up to $17 \mathrm{~m}^{3}$.

According to [4], aggregates of Cooljet series offered by the Kerstner can have a drive from a compressor installed in the vehicle's engine or from an alternator. They can be optionally equipped with $230 \mathrm{~V}$ stationary drive or heating option. The electric aggregates can be temporarily powered by an additional battery when the vehicle's engine is turned off. Then the voltage level is monitored to ensure trouble-free re-start of the engine. The devices are offered in the cooling range up to 0 or $-20^{\circ} \mathrm{C}$. All units are equipped with an automatic defrost function. Kerstner is also a producer of insulation with permeability parameters $\mathrm{K}<0.4 \mathrm{~W} / \mathrm{mK}$, having ATP certificates. Due to the high insulation parameters and the aerodynamic shape of the device, the aggregates are not oversized, which has a positive effect on their life, quiet operation and, above all, low fuel consumption. 
Also, according to [4] the Eberspaecher company offers two cooling solutions. The traditional refrigeration unit Frosty 700 with electric drive is available in two versions. With power supply only from the $12 \mathrm{~V}$ car and with power from the car installation and at the standstill from the $230 \mathrm{~V}$ socket. Cooling power of this unit with $12 \mathrm{~V}$ power reaches $830 \mathrm{~W}$. The device with a flow of $700 \mathrm{~m}^{3} / \mathrm{h}$ of air guarantees an ideal temperature in small vehicles with body isothermal. The condenser is mounted on the roof, while the evaporator can be placed under the roof or on the bulkhead wall in the cargo space. A completely different solution proposed by this company are refrigerators. The system under the name Coolbox is a replaceable refrigeration box with its own unit, which can maintain a constant temperature of the transported goods at the level of even $24^{\circ} \mathrm{C}$. Cooling containers are available in eight sizes: from a very small 22-liter weighing $15 \mathrm{~kg}$ up to a heavy $80 \mathrm{~kg}$ volume of 330 litters. They can be powered by 12 or $24 \mathrm{~V}$ and from $230 \mathrm{~V}$ mains. This system does not require the car to be processed and can be used as a cold storage for temporary use. It also allows you to leave the product together with the refrigeration box.

\section{SUMMARY}

The review of modern solution for refrigeration trucks has been done. The most important manufacturers of refrigerated trailers have been described. Also, very popular solutions based on the adaptation of vehicle for refrigeration have been discussed. Characteristics of popular semi-trails, trailers and bodies used as refrigerator units are shortly described. Recently, modern refrigerator trucks have started using some telematic systems presented in the article. Different types of aggregates have been also discussed.

\section{BIBLIOGRAFIA}

1. Jurczak M., Chłód w ładowni, Truck\&Machines nr 4/2017, pp 16-19

2. https://www.cargobull.com/en/trailer-for-transport-andlogistics_46_634.html, Available on 2018.02.20

3. Kögel Cool - PurFerro quality, chłodny mistrz klasy premium, TRUCKauto.pl: 2015/7-10

4. Donda M., Chłód na żądanie, Truck\&Van nr 4/2012, pp. 19-22

5. http://www.thermoking.com.pl/naczepy-i-przyczepy, Available on 2018.02.20

6. Samochodowe agregaty chłodnicze Carrier Transicold. Available on 2018.02.20 at

http://www.termotrans.com.pl/agregaty_chlodnicze.html.

7. Carrier Transicold to Offer Telematics System for Transport Refrigeration Units. Available on 2018.02.20 at www.transicold.carrier.com

8. http://antyweb.pl/blulog-izotermiczne-pojemniki-nfcl

9. http://www.termpol.com.pl/?id=p0300\&p=137

10. http://www.konvekta.de/produkte.html. Available on 2018.02.20

\section{Nowoczesne samochody dla chłodnictwa}

Artykut zawiera przeglad nowoczesnych rozwiazań dla pojazdów chłodniczych. Opisano najwazniejszych producentów naczep chłodniczych. Omówiono rozwiazania oparte na adaptacji pojazdu do chtodnictwa. Przedstawiono charakterystyki popularnych naczep, przyczep i nadwozi wykorzystywanych jako chłodnie. Omówiono systemy telematyczne $i$ agregaty stosowane $w$ samochodach chtodniczych.

Autorzy:

Krystian Siczek - student of Lodz University of Technology

Krzysztof Siczek - Lodz University of Technology

JEL: L62 DOI: 10.24136/atest.2018.163

Data zgłoszenia: 2018.05.24 Data akceptacji: 2018.06.15 